\title{
Potential Negative Effects of Antimicrobial Allergy Labelling on Patient Care: A Systematic Review
}

\author{
Julie Hui-Chih Wu, Bradley J Langford, Kevin L Schwartz, Rosemary Zvonar, Sumit Raybardhan, \\ Valerie Leung, and Gary Garber
}

\begin{abstract}
Background: Antimicrobial allergy labels, either self-reported or placed in a patient's medical record, are common, but in many cases they are not associated with a true immunoglobulin E-mediated allergic response.
\end{abstract}

Objective: To assess the impact of antimicrobial allergy labels on antimicrobial prescribing, resource utilization, and clinical outcomes.

Data Sources: The MEDLINE, Embase, CINAHL, and Scopus electronic databases were searched for the period 1990 to January 2016.

Study Selection: Controlled studies with the objective of assessing antimicrobial prescribing, resource utilization, and/or clinical outcomes associated with antimicrobial allergy labels were included.

Results: The search identified 560 unique citations, of which 7 articles met the inclusion criteria. One additional article identified by an expert in the field was also included. Four of the identified papers were limited to penicillin or other B-lactam allergies. Six studies noted differences in antibiotic selection between patients with allergy labels and those without such labels. Broader-spectrum or second-line agents (e.g., vancomycin, clindamycin, and fluoroquinolones) were more commonly prescribed for patients with penicillin allergy labels. Antibiotic therapy costs were significantly higher for patients with allergy labels than for those without. The impact of allergy labels on clinical outcomes was mixed. One study indicated a longer length of hospital stay, 2 studies reported higher readmission rates, and 1 study reported a higher rate of antibiotic-resistant organisms for patients with allergy labels.

Conclusions: Most of the available literature is limited to penicillin or ß-lactam allergy. The growing body of knowledge supports the concept that B-lactam allergy labels are not benign and that labelling in the absence of a true allergy has a negative effect on patient care. Allergy labelling appears to be associated with suboptimal antibiotic selection, greater treatment costs, prolonged length of stay, greater readmission rates, and higher prevalence of antibiotic-resistant organisms. There is an opportunity for antimicrobial stewardship programs to implement systematic allergy verification to optimize antimicrobial therapy and improve patient care.

Keywords: antimicrobial allergy labels, antibiotic allergy, antimicrobial stewardship, antibiotic stewardship

\section{RÉSUMÉ}

Contexte: Les mentions d'allergies aux antimicrobiens, soit autodéclarées soit consignées dans un dossier médical, sont fréquentes, mais dans bien des cas elles ne signalent pas une véritable réaction allergique à médiation par l'immunoglobuline E.

Objectif : Évaluer l'effet des mentions d'allergie aux antimicrobiens sur les habitudes de prescription d'antimicrobiens, l'utilisation des ressources et les résultats cliniques.

Sources des données : Les bases de données numériques MEDLINE, Embase, CINAHL et Scopus ont été interrogées pour la période allant de 1990 à janvier 2016.

Sélection des études : Les essais cliniques comparatifs dont l'objectif était d'évaluer les habitudes de prescription d'antimicrobiens, l'utilisation des ressources ou les résultats cliniques associés aux mentions d'allergie aux antimicrobiens ont été inclus.

Résultats : La recherche a permis de trouver 560 citations distinctes et ainsi de repérer sept articles qui répondaient aux critères d'inclusion. Un article supplémentaire signalé par un expert du domaine a été inclus à l'analyse. Quatre de ces articles se limitaient aux allergies à la pénicilline ou à d'autres ß-lactamines. Six études ont noté des différences dans le choix des antibiotiques entre les patients ayant une mention d'allergie à leur dossier et ceux n'en ayant pas. Des antibiotiques à plus large spectre ou des médicaments de deuxième intention (comme la vancomycine, la clindamycine et les fluoroquinolones) étaient plus souvent prescrits pour les patients ayant une mention d'allergie à la pénicilline. Les coûts des antibiothérapies étaient significativement plus élevés pour les patients ayant une mention d'allergie que pour ceux n'en ayant pas à leur dossier. L'effet des mentions d'allergie sur les résultats cliniques était inégal. Une étude indiquait un séjour plus long à l'hôpital, deux études indiquaient des taux de réadmission plus élevés et une étude indiquait un taux plus élevé d'organismes résistants aux antibiotiques pour les patients ayant une mention d'allergie comparativement à ceux n'en ayant pas.

Conclusions : La majeure partie des articles disponibles se limitent aux allergies à la pénicilline ou à d'autres ß-lactamines. De plus en plus, le savoir vient appuyer le concept voulant que les mentions d'allergies aux ß-lactamines ne soient pas bénignes et que leur emploi en l'absence d'une allergie réelle ait un effet négatif sur les soins aux patients. Les mentions d'allergie semblent être associées à un choix sous-optimal d'antibiotiques, des coûts de traitement plus élevés, des séjours plus longs, des taux de réadmission plus élevés et une plus grande prévalence d'organismes résistants aux antibiotiques. Or, les programmes de gérance des antimicrobiens pourraient permettre de mettre 
en œuvre des procédures de vérification systématique des allergies afin d'optimiser l'antibiothérapie et d'améliorer les soins aux patients.

\section{INTRODUCTION}

A

ntibiotic resistance is a growing public health problem, with substantial burden throughout the health care system. ${ }^{1}$ It is generally recognized that inappropriate antibiotic prescribing and unnecessary use of broad-spectrum antibiotics contribute to antibiotic resistance. Both inappropriate antibiotic prescribing and antibiotic resistance are associated with increased morbidity and mortality. ${ }^{2,3}$

Although many patients report or have a medical record of antimicrobial allergies, referred to as "allergy labels", not all of these allergy labels are accurate. Inaccurate antimicrobial allergy labelling contributes to inappropriate antibiotic selection through prescribers' avoidance of first-line or narrow-spectrum antibiotics. This can result in the use of broader-spectrum antibiotics, suboptimal therapy, and increased risks of antibiotic resistance and adverse events, as well as increased costs. ${ }^{4}$ Reporting of antibiotic allergies is common. Trubiano and others ${ }^{5}$ stated that $25 \%$ of patients admitted to hospital had documentation of an antimicrobial allergy, with $70 \%$ of these allergies involving B-lactams. Although the prevalence of reported ß-lactam allergies is high, confirmed (true) allergic reactions are less common. For example, Park and others ${ }^{6}$ showed that $96 \%$ of patients with a self-reported penicillin allergy did not have a true immunoglobulin E ( $\mathrm{IgE}$ )-mediated allergy based on penicillin skin testing. ${ }^{6}$ Reporting rates of true allergies to classes of antimicrobials other than B-lactams are scarce.

Antimicrobial stewardship programs aim to optimize antimicrobial use, thereby improving patient outcomes, minimizing adverse effects, and reducing Clostridium difficile infections and the development of antimicrobial resistance. ${ }^{7}$ A greater understanding of the impact of antimicrobial allergy labels can provide an impetus for improved allergy verification strategies, aimed at optimizing selection of antimicrobial therapy and patient outcomes.

This systematic review was performed to answer the following 3 separate but related questions: What is the impact of antimicrobial allergy labels on antimicrobial prescribing (e.g., choice and duration of therapy)? Do antimicrobial allergy labels increase health care costs and resource utilization? What is the effect of antimicrobial allergy labels on clinical outcomes (e.g., hospital length of stay, readmission rates, and mortality)?

\section{METHODS}

Searches for English-language articles published since 1990 were conducted in 4 databases (initially performed in
MEDLINE and adapted into Embase, CINAHL, and Scopus) on January 18 and 21, 2016, by Public Health Ontario Library Services. The search concepts were "antimicrobial/antibiotic allergy label", "antimicrobial/antibiotic", and "patient/prescribing/ utilization outcomes". Both primary literature and review articles were included. The full search strategy is available in Appendix 1 (see https://www.cjhp-online.ca/index.php/cjhp/ issue/view/125/show Toc).

English-language articles retrieved by the searches were assessed for eligibility. To ensure that the review would be comprehensive, there were no restrictions on study design, population, antimicrobial allergy, health care setting, or outcomes. Articles were included if the objective of the research was to assess the impact of antimicrobial allergy labels, relative to a control group, on antimicrobial prescribing, resource utilization, and/or clinical outcomes. Case reports and studies involving non-antimicrobial allergies, the efficacy or safety of antimicrobial allergy testing, or drug intolerance were excluded. Title and abstract screening, as well as full-text screening, was performed individually in duplicate by 2 reviewers (J.H.C.W. and B.J.L.). Data for overall results (e.g., allergy label versus control) were extracted by one of these reviewers (J.H.C.W.), with extraction verified by the second reviewer (B.J.L.) for $20 \%$ of the articles. Any disagreements regarding inclusion or data abstraction were resolved by consensus. Subgroup analyses, such as female versus male, were excluded. Results that did not reach statistical significance were recorded as not different from the control group. Because the inclusion criteria were broad (with inclusion of studies examining any allergy label, population, age, setting, and outcome), a descriptive analysis was performed.

\section{RESULTS}

The search identified 560 unique citations, with 7 articles meeting the inclusion criteria. During the review process, 1 additional article was identified by an expert in the field and was included. No reviews were found. Therefore, a total of 8 articles were included in the analysis ${ }^{5,8-14}$ (Table 1 ).

The publication year of the included articles ranged from 2000 to 2015. Four studies were conducted in the United States, ${ }^{8-10,14} 2$ in Australia, ${ }^{5,12} 1$ in Canada, ${ }^{13}$ and 1 in Israel. ${ }^{11}$ The studies varied with respect to population (e.g., patients with penicillin allergy or any antimicrobial allergy), comparator (e.g., matched controls, patients with no antimicrobial allergies), methodology, and outcomes assessed (see Table 1). 
This single copy is for your personal, non-commercial use only.

For permission to reprint multiple copies or to order presentation-ready copies for distribution, contact CJHP at publications@cshp.ca

Table 1 (part 1 of 2). Summary of Studies Included in a Systematic Review of Antimicrobial Allergy Labelling

\begin{tabular}{|c|c|c|c|c|c|}
\hline Reference & Study Objective(s) & Study Design & Country and Setting & $\begin{array}{l}\text { Population and } \\
\text { Sample Size }\end{array}$ & $\begin{array}{l}\text { Outcome Type } \\
\text { Reported }\end{array}$ \\
\hline $\begin{array}{l}\text { Charneski et al. } \\
2011^{8}\end{array}$ & $\begin{array}{l}\text { To determine the impact } \\
\text { of an antimicrobial } \\
\text { allergy label in the } \\
\text { medical record on } \\
\text { clinical outcomes in } \\
\text { hospitalized patients }\end{array}$ & $\begin{array}{l}\text { Retrospective } \\
\text { cohort study }\end{array}$ & $\begin{array}{l}\text { United States: urban } \\
\text { academic teaching } \\
\text { hospital; nonsurgical } \\
\text { patient care ward }\end{array}$ & $\begin{array}{l}\text { Age } \geq 20 \text { years, received } \\
\text { at least } 1 \text { antimicrobial } \\
\text { prescription }(n=11872)\end{array}$ & $\begin{array}{l}\text { Clinical } \\
\text { - Length of stay } \\
\text { - ICU admission rate } \\
\text { - Death } \\
\text { - Readmission within } \\
4 \text { weeks of discharge } \\
\text { Prescribing } \\
\text { - Received > } 1 \text { antimicrobial }\end{array}$ \\
\hline $\begin{array}{l}\text { Lutomski et al. } \\
2008^{14}\end{array}$ & $\begin{array}{l}\text { To determine the } \\
\text { frequency with which } \\
\text { reported antibiotic } \\
\text { allergies alter drug } \\
\text { selection and to assess } \\
\text { the validity of these } \\
\text { allergies }\end{array}$ & $\begin{array}{l}\text { Retrospective } \\
\text { cohort study }\end{array}$ & $\begin{array}{l}\text { United States: tertiary } \\
\text { care teaching hospital; } \\
\text { inpatients }\end{array}$ & $\begin{array}{l}\text { Age } \geq 18 \text { years, at least } \\
1 \text { documented antibiotic } \\
\text { allergy, and received } \\
\text { antibiotic during hospital } \\
\text { admission }(n=300)\end{array}$ & $\begin{array}{l}\text { Prescribing } \\
\text { - Antibacterial regimen } \\
\text { - Most frequently selected } \\
\quad \text { alternative agents }\end{array}$ \\
\hline $\begin{array}{l}\text { MacLaughlin et al. } \\
2000^{9}\end{array}$ & $\begin{array}{l}\text { To evaluate effects of } \\
\text { reported } B \text {-lactam } \\
\text { allergies on antibiotic } \\
\text { selection and cost }\end{array}$ & $\begin{array}{l}\text { Retrospective } \\
\text { cohort study }\end{array}$ & $\begin{array}{l}\text { United States: university- } \\
\text { based family medicine } \\
\text { clinic; ambulatory } \\
\text { patients }\end{array}$ & $\begin{array}{l}\text { Patients of any age who } \\
\text { received antibiotic for } \\
\text { upper respiratory tract } \\
\text { infection, otitis media, } \\
\text { sinusitis (acute or chronic), } \\
\text { and/or urinary tract } \\
\text { infection ( } n=660)\end{array}$ & $\begin{array}{l}\text { Prescribing } \\
\text { - Antibiotic selection } \\
\text { (cephalosporin, } \\
\text { macrolide) } \\
\text { Utilization } \\
\text { - Antibiotic costs }\end{array}$ \\
\hline $\begin{array}{l}\text { Macy and Contreras } \\
2014^{10}\end{array}$ & $\begin{array}{l}\text { To determine total } \\
\text { hospital days, antibiotic } \\
\text { exposure, and } \\
\text { prevalence rates of } \\
\text { Clostridium difficile, } \\
\text { MRSA, and VRE in } \\
\text { patients with and } \\
\text { without penicillin allergy } \\
\text { labels upon admission }\end{array}$ & $\begin{array}{l}\text { Retrospective } \\
\text { matched-control } \\
\text { cohort study }\end{array}$ & $\begin{array}{l}\text { United States: multiple } \\
\text { hospitals (hospital type } \\
\text { not specified); any } \\
\text { admitted patient }\end{array}$ & $\begin{array}{l}\text { Age not specified } \\
(n=154746)\end{array}$ & $\begin{array}{l}\text { Clinical } \\
\text { - Length of stay } \\
\text { - C. difficile prevalence } \\
\text { - MRSA prevalence } \\
\text { - VRE prevalence } \\
\text { Prescribing } \\
\text { - Antibiotic selection } \\
\text { (fluoroquinolones, } \\
\text { ciprofloxacin, vancomycin, } \\
\text { clindamycin, } \\
\text { cephalosporin) } \\
\text { Utilization } \\
\text { - Total hospital costs }\end{array}$ \\
\hline $\begin{array}{l}\text { Picard et al. } \\
2013^{13}\end{array}$ & $\begin{array}{l}\text { To determine how } \\
\text { physicians at a large } \\
\text { Canadian tertiary care } \\
\text { academic hospital } \\
\text { without allergists on } \\
\text { staff treat patients with } \\
\text { a history of penicillin } \\
\text { allergy }\end{array}$ & $\begin{array}{l}\text { Retrospective } \\
\text { cohort study }\end{array}$ & $\begin{array}{l}\text { Canada: tertiary care } \\
\text { academic hospital; ICU, } \\
\text { coronary care unit, } \\
\text { internal medicine wards }\end{array}$ & $\begin{array}{l}\text { Age not specified; } \\
\text { penicillin allergy labelled } \\
(n=172)\end{array}$ & $\begin{array}{l}\text { Utilization } \\
\text { - Cost (additional cost of } \\
\text { alternative antibiotics } \\
\text { in place of B-lactam } \\
\text { standard of care) } \\
\text { Prescibing } \\
\text { - Antibiotic selection } \\
\text { (fluoroquinolones, } \\
\text { vancomycin) }\end{array}$ \\
\hline $\begin{array}{l}\text { Sade et al. } \\
2003^{11}\end{array}$ & $\begin{array}{l}\text { To examine the } \\
\text { difference in cost and } \\
\text { antibiotic usage } \\
\text { between patients with } \\
\text { and without penicillin } \\
\text { allergy labels }\end{array}$ & $\begin{array}{l}\text { Retrospective } \\
\text { matched-control } \\
\text { cohort study }\end{array}$ & $\begin{array}{l}\text { Israel: tertiary level } \\
\text { teaching hospital; internal } \\
\text { medicine ward }\end{array}$ & $\begin{array}{l}\text { Age not specified; } \\
\text { penicillin allergy labelled } \\
\text { by physician }(n=236)\end{array}$ & $\begin{array}{l}\text { Clinical } \\
\text { - Death } \\
\text { - Length of stay } \\
\text { Prescribing } \\
\text { - Antibiotic selection } \\
\text { (cephalosporin, macrolide, } \\
\text { vancomycin) } \\
\text { - No. of antibiotics used } \\
\text { during treatment } \\
\text { - Route of antibiotic } \\
\text { administration } \\
\text { - Frequency of drug } \\
\text { administration } \\
\text { - Duration of therapy } \\
\text { Utilization } \\
\text { - Antibiotic costs during } \\
\text { hospitalization } \\
\text { - Antibiotic costs after } \\
\text { hospitalization }\end{array}$ \\
\hline
\end{tabular}


This single copy is for your personal, non-commercial use only.

For permission to reprint multiple copies or to order presentation-ready copies for distribution, contact CJHP at publications@cshp.ca

Table 1 (part 2 of 2). Summary of Studies Included in a Systematic Review of Antimicrobial Allergy Labelling

\begin{tabular}{|c|c|c|c|c|c|}
\hline Reference & Study Objective(s) & Study Design & Country and Setting & $\begin{array}{c}\text { Population and } \\
\text { Sample Size }\end{array}$ & $\begin{array}{l}\text { Outcome Type } \\
\text { Reported }\end{array}$ \\
\hline $\begin{array}{l}\text { Trubiano et al. } \\
2015^{5}\end{array}$ & $\begin{array}{l}\text { To examine the rate of } \\
\text { antimicrobial allergy } \\
\text { labelling at a tertiary } \\
\text { referral centre and } \\
\text { impacts on antimicrobial } \\
\text { usage and } \\
\text { appropriateness }\end{array}$ & $\begin{array}{l}\text { Two inpatient } \\
\text { antimicrobial } \\
\text { prevalence } \\
\text { surveys }\end{array}$ & $\begin{array}{l}\text { Australia: tertiary referral } \\
\text { centre; inpatients }\end{array}$ & $\begin{array}{l}\text { Inclusion criteria not } \\
\text { specified }(n=509)\end{array}$ & $\begin{array}{l}\text { Prescribing } \\
\text { - Antibiotic selection } \\
\text { (cephalosporin, } \\
\text { B-lactams) } \\
\text { - Duration of antimicrobial } \\
\text { therapy } \\
\text { - Inappropriate antimicrobial } \\
\text { prescribing } \\
\text { - Route of antimicrobial } \\
\text { administration } \\
\text { - Antimicrobial exposure } \\
\text { days }\end{array}$ \\
\hline $\begin{array}{l}\text { Trubiano et al. } \\
2015^{12}\end{array}$ & $\begin{array}{l}\text { To (1) determine the } \\
\text { prevalence of } \\
\text { antimicrobial allergy } \\
\text { labels in patients with } \\
\text { cancer; (2) provide a } \\
\text { description of reported } \\
\text { antibiotic allergies; } \\
\text { and (3) describe the } \\
\text { impacts of an } \\
\text { antimicrobial allergy } \\
\text { label on antimicrobial } \\
\text { choice, usage, and } \\
\text { clinical outcomes }\end{array}$ & $\begin{array}{l}\text { Retrospective } \\
\text { cohort study }\end{array}$ & $\begin{array}{l}\text { Australia: tertiary referral } \\
\text { centre for cancer } \\
\text { patients; oncology, } \\
\text { hematology }\end{array}$ & $\begin{array}{l}\text { Age not specified; patients } \\
\text { coded as having an } \\
\text { infective diagnosis who } \\
\text { received antimicrobial } \\
\text { agent for treatment of } \\
\text { infection, with inpatient } \\
\text { admission }>24 \mathrm{~h} \\
(n=198)\end{array}$ & $\begin{array}{l}\text { Clinical } \\
\text { - 30-day or 60-day } \\
\text { mortality } \\
\text { - Length of stay } \\
\text { - Overall readmissions } \\
\text { - Readmissions with } \\
\text { infectious disease } \\
\text { diagnosis requiring } \\
\text { antimicrobial therapy } \\
\text { Prescribing } \\
\text { - Antibiotic selection } \\
\text { (fluoroquinolone) } \\
\text { - Antibiotics used per } \\
\text { admission } \\
\text { - Antibiotic duration } \\
\text { - Concordance with } \\
\text { first-line therapy } \\
\text { - No. of antibiotics } \\
\text { employed }\end{array}$ \\
\hline
\end{tabular}

$\overline{\mathrm{ICU}}=$ intensive care unit, MRSA = multidrug-resistant Staphylococcus aureus, VRE = vancomycin-resistant Enterococcus.

Two studies included only adult patients. ${ }^{8,14}$ Seven of the 8 studies focused on inpatients, ${ }^{5,8,10-14}$ and the other study focused on outpatients. ${ }^{9}$ Four studies included patients labelled as having any type of antimicrobial allergy, ${ }^{5,8,12,14} 3$ studies focused on penicillin allergy,,$^{10,11,13}$ and 1 study included any $\beta$-lactam allergy. ${ }^{9}$ None of the studies reported the source of the allergy labels (e.g., patient self-report or documented reaction). Three of the 4 studies that were not limited to B-lactam allergies reported the prevalence of allergies to specific agents. Although allergies to penicillin and other ß-lactams were most common, $11 \%-21 \%$ of reported allergies were to sulfonamides, $7 \%$ to vancomycin, and less than $6 \%$ to each of fluoroquinolones, metronidazole, macrolides, and doxycycline..$^{5,12,14}$

\section{Prescribing Outcomes}

Prescribing outcomes were reported in all 8 of the included studies. The prescribing outcomes considered were antimicrobial selection, duration of therapy, and appropriateness. Seven of the 8 studies reported differences in antibiotic selection between patients with allergy labels and controls. ${ }^{5,9-14}$

Alternative antibiotics were significantly more likely to be used for patients with penicillin allergy labels than for those without ( $38 \%$ versus $15 \%, p<0.0001$ ), as well as for those with cephalosporin allergy labels than for those without (55\% versus $27 \%, p=0.0007) \cdot{ }^{14}$ Patients with allergy labels were more likely to receive cephalosporins ${ }^{9,11,12}$ (including first- to fourthgeneration cephalosporins, $p<0.001^{11,12}$ ) and non- $\beta$-lactam antibiotics. ${ }^{5,9,10,12-14}$ Non- $\beta$-lactam antibiotics that were used more frequently for patients with an allergy label were clindamycin, ${ }^{10,14}$ vancomycin, ${ }^{10,11,13,14}$ macrolides, ${ }^{9,11}$ and fluoroquinolones. ${ }^{10-14}$ In contrast, significantly lower cephalosporin use was noted for patients reported to have penicillin allergy relative to controls in 2 studies ( $24 \%$ versus $43 \%, p=0.05^{5}$; $32 \%$ versus $\left.50 \%, p<0.0001^{10}\right)$, including first-generation cephalosporins (16\% versus $33 \%, p<0.0001)$ and thirdgeneration or higher cephalosporins $(20 \%$ versus $23 \%$, $p<0.0001) .{ }^{10}$

In the study by Sade and others, ${ }^{11}$ a penicillin allergy label had no effect on the number of antibiotics prescribed, the number of antibiotics given parenterally, the duration of antibiotic therapy, or the frequency of administration. However, other studies identified significantly higher numbers of antibiotics employed (odds ratio [OR] 1.51, 95\% confidence interval [CI] $\left.1.33-1.70^{8}\right)$ among patients with allergy labels than among those without allergy (average of 3 versus 2 antibiotics per admission, $p=0.01){ }^{12}$ 
Trubiano and others ${ }^{12}$ reported that the presence of an allergy label was associated with a longer course of antibiotic therapy in hospitalized cancer patients after multivariable adjustment $(p=0.03)$. In another study, Trubiano and others ${ }^{5}$ observed a significantly longer antibiotic duration for patients admitted to a tertiary care hospital (median duration 6 versus 4 days, $p=0.018$ ) and a significantly higher use of IV relative to oral antibiotics in patients with an allergy label ( $60 \%$ versus $46 \%, p=0.0001)$.

Trubiano and others ${ }^{5}$ found no statistically significant difference between patients with allergy labels and those without in terms of appropriate antibiotic selection (using criteria from the National Antimicrobial Prescribing Survey of Australia; 29\% versus $23 \%, p=0.22$ ) or the use of restricted antimicrobials ( $25 \%$ versus $24 \%, p=0.44)$. However, in a different study, Trubiano and others ${ }^{12}$ observed significantly less concordance with prescribing guidelines for patients with an antimicrobial allergy label ( $47 \%$ versus $91 \%, p<0.001$ ); Lutomski and others ${ }^{14}$ also observed $30 \%$ deviation from standard of care (no statistical analysis reported).

\section{Utilization Outcomes}

Four studies reported on costs as a utilization outcome. Three of these reported antibiotic costs ${ }^{9,11,13}$ and 1 translated hospital length of stay and total hospital use into financial costs. ${ }^{10}$

MacLaughlin and others ${ }^{9}$ examined patients for whom antibiotics were prescribed in a family medicine clinic and observed a significantly higher mean antibiotic cost for individuals with a ß-lactam allergy label than for those without $(65 \%$ higher). Similarly, if a penicillin allergy label was present, there were significantly higher costs for antibiotic therapy during hospital admission (56\% higher) and after discharge (38\% higher). ${ }^{11}$ A Canadian study conducted in 2009 by Picard and others ${ }^{13}$ found that the use of alternative antibiotics in place of standard-of-care $ß$-lactam regimens carried an additional cost of Can $\$ 326.50$ per patient. Finally, the observed average increase in length of stay- 0.59 days per penicillin-allergic patient-in a US hospital translated to an estimated total of US\$64 626630 over the study period (2010-2012). ${ }^{10}$ This increased expenditure was reported to be approximately 9.5 times greater than the cost of conducting penicillin allergy testing in those patients. ${ }^{10}$

\section{Clinical Outcomes}

Clinical outcomes, reported by 4 studies, included length of stay, ${ }^{8,10-12}$ readmission, ${ }^{8,12}$ and death. ${ }^{8,11,12}$ Overall, the effects of allergy labels on the various clinical outcomes were mixed.

Of the 4 studies assessing hospital length of stay, 2 studies indicated an increase among those with allergy labels (by 0.59 days $[95 \% \text { CI } 0.47-0.71]^{10}$ and by 1.16 days $\left.^{8}\right)$, whereas the other 2 studies reported no significant difference ${ }^{11,12}$ Two studies reported admission and readmission rates. ${ }^{8,12}$ One of these studies reported a significantly higher ICU admission rate (adjusted OR 1.42, 95\% CI 1.21-1.67), ${ }^{8}$ and the other reported a higher readmission rate due to diagnosis of an infectious disease requiring antimicrobial therapy in patients labelled as having an antimicrobial allergy (adjusted OR 3.27, 95\% CI 1.55-6.88). ${ }^{12}$ However, presence of an allergy label was not significantly associated with an increased overall risk of readmission (adjusted OR $1.99,95 \%$ CI $0.95-4.15)^{12}$ or the readmission rate within 4 weeks of discharge (adjusted OR 0.71, 95\% CI $0.63-0.80) .{ }^{8}$ Mixed results were also observed for the mortality outcome. Two studies found no difference in 30-and 60-day mortality ${ }^{12}$ or in-hospital mortality, ${ }^{11}$ whereas Charneski and others ${ }^{8}$ indicated that patients with an antimicrobial allergy label had a significantly higher risk of in-hospital death (adjusted OR 1.56, 95\% CI 1.20-2.04) relative to those with no reported allergy. The presence of a penicillin allergy label was associated with significantly higher prevalences of infection with C. difficile (OR 1.23, 95\% CI 1.16-1.32), methicillin-resistant Staphylococcus aureus (OR 1.14, 95\% CI 1.07-1.32), and vancomycin-resistant Enterococcus (OR 1.30, 95\% CI 1.13-1.50). ${ }^{10}$

\section{DISCUSSION}

This systematic review assessed the potential negative impact of antimicrobial allergy labels on patient care. Although results varied, the studies included in this review found that reported antimicrobial allergies may be associated with worse clinical outcomes, including longer hospital stay, ${ }^{8,10}$ higher readmission rates, ${ }^{8,12}$ and higher mortality, ${ }^{8}$ with increased treatment costs relative to those without allergies. ${ }^{9-11,13}$ Given that antimicrobial allergy labels are common at the time of hospital admission, at a frequency ranging from $6 \%{ }^{11}$ to as high as $25 \%,{ }^{5}$ these negative clinical consequences have the potential to affect a large population.

In addition to their association with negative clinical outcomes, antimicrobial allergy labels may also lead to potentially unnecessary use of broad-spectrum antibiotics. B-Lactams are frequently considered as first-line agents for many infections, given their proven clinical efficacy, safety, tolerability, and low propensity for drug interactions. ${ }^{15-17}$ Use of alternative agents (e.g., vancomycin for serious infections due to methicillinsusceptible $S$. aureus) can compromise clinical efficacy. ${ }^{18,19}$ Furthermore, alternative agents such as clindamycin and fluoroquinolones, which are frequently used for patients with allergy to penicillin or cephalosporin, have been associated with an increase in frequency of $C$. difficile infection. ${ }^{10,20,21}$ In addition, the use of broader-spectrum agents and a greater number of antibiotics for a longer treatment course increases costs and the risk of antimicrobial resistance. ${ }^{4,9}$ 
Many of the studies included in this review described differences in antibiotic selection between patients with and without allergy labels, but few commented on the appropriateness of the chosen therapy. This may be because appropriateness of therapy is more difficult to assess, despite it being a key component of antimicrobial stewardship. Notably, most of the studies involved hospital inpatients. As a result, less insight is available regarding the outcomes of allergy labels in community practice.

Accurately assessing reported allergies to provide the best antimicrobial therapy is an important antimicrobial stewardship initiative. ${ }^{7}$ Studies assessing allergy verification procedures have found that $84 \%$ to $99 \%$ of those with self-reported penicillin allergy are found to not have a true allergy and thus can be "de-labelled". ${ }^{6,22-27}$ Hence, it is important for clinicians to carefully evaluate allergy status before prescribing alternative antimicrobial therapy. Allergy labels should be assessed through a detailed clinical history characterizing the type and timing of previous reactions. Many ß-lactams are well tolerated by patients with a history of penicillin allergy. For instance, cephalosporins can be safely administered to patients with a self-reported history of penicillin allergic reaction that occurred more than 10 years ago or if prior reactions did not include features of an IgEmediated response, such as hives or anaphylaxis. ${ }^{28,29}$

Antibiotic allergy testing, in the form of a skin test, can be performed by trained health care professionals to help optimize antimicrobial use. ${ }^{30} \mathrm{~A}$ recent systematic review and meta-analysis of penicillin allergy verification interventions found that penicillin skin testing was the most commonly reported method of allergy verification. ${ }^{31}$ Allergy consultation before skin testing and pharmacy-driven interviews were other approaches. ${ }^{31} \mathrm{In}$ particular, penicillin skin testing was found to be a safe and effective way to clarify allergy status in inpatient settings. In addition, ruling out penicillin allergy was shown to decrease health care costs and influence antibiotic selection, with increased prescribing of penicillin and cephalosporin and reduced prescribing of vancomycin and fluoroquinolone. ${ }^{31}$ Antimicrobial stewardship teams are encouraged to incorporate antibiotic allergy evaluation and testing into their programs. ${ }^{32}$

This review had some limitations. All relevant articles identified in the search were included in the analysis, because only a limited number of published studies were found. A quality assessment was not conducted, and therefore no exclusion criteria based on study quality were applied. There was substantial heterogeneity in the population and outcomes reported, which made it difficult to draw generalizable conclusions. All studies were retrospective in nature, introducing the possibility of unmeasured confounding factors. Many studies reported on differences in antibiotic selection between patients with and without antimicrobial allergies, but less frequently reported on appropriateness or clinical outcomes. As a result, definitive conclusions about the clinical impact of allergy labels will require further studies. Additionally, outcomes related to resolution of infection and adverse events were not reported in any of the studies, although these are important considerations when first-line antibiotics are not selected. Finally, most of the studies were hospital-based and focused on B-lactam antibiotics; therefore, this review may not be generalizable to non- $B$-lactam allergy labels or to patients in settings other than acute care hospitals.

The lack of review articles and the presence of only a handful of primary studies addressing the impact of antimicrobial allergy labels indicate a shortage of research in this area. However, it is evident from the data reported in this review and recent publications ${ }^{33-36}$ that inaccurate antimicrobial allergy labels are associated with several important negative impacts on antimicrobial prescribing, patient care, and hospital resources. For example, one prospective study conducted in 3 academic hospitals in Toronto, and published after this review was completed, also identified an increased rate of adverse outcomes (particularly readmission to hospital and adverse drug reactions) among patients who received non-preferred therapy as a result of reported B-lactam allergy. ${ }^{36} \mathrm{~A}$ multicentre prospective evaluation of point-of-care $\beta$-lactam allergy skin testing by antimicrobial stewardship teams demonstrated the feasibility of systematic allergy verification as well as increased use of preferred ß-lactam therapy in acute care hospitals without any increase in the risk of adverse drug reactions. ${ }^{30} \mathrm{~A}$ growing body of antimicrobial stewardship initiatives targeted toward patients with reported B-lactam allergies further emphasizes the benefit of allergy verification in this population. ${ }^{31,37}$ The impact of nonß-lactam allergy labels is not as well documented and may require further study.

\section{CONCLUSION}

This systematic review provides data to support antimicrobial stewardship programs in improving the appropriateness of antimicrobial therapy for patients labelled as having antimicrobial allergies. Policies and procedures to ensure systematic verification of allergies and selection of optimal antimicrobial therapy should be employed.

\section{References}

1. Davey PG, Marwick C. Appropriate vs. inappropriate antimicrobial therapy. Clin Microbiol Infect. 2008;14 Suppl 3:15-21.

2. Kumar A, Ellis P, Arabi Y, Roberts D, Light B, Parrillo JE, et al. Initiation of inappropriate antimicrobial therapy results in a fivefold reduction of survival in human septic shock. Chest. 2009;136(5):1237-48.

3. De Kraker MEA, Davey PG, Grundmann H; BURDEN study group. Mortality and hospital stay associated with resistant Staphylococcus aureus and Escherichia coli bacteremia: estimating the burden of antibiotic resistance in Europe. PLoS Med. 2011;8(10):e1001104.

4. Joint Task Force on Practice Parameters; American Academy of Allergy, Asthma and Immunology; American College of Allergy, Asthma and Immunology; Joint Council of Allergy, Asthma and Immunology. Drug allergy: an updated practice parameter. Ann Allergy Asthma Immunol. 2010; 105(4):259-73. 
This single copy is for your personal, non-commercial use only.

For permission to reprint multiple copies or to order presentation-ready copies for distribution, contact CHHP at publications@cshp.ca

5. Trubiano JA, Cairns KA, Evans JA, Ding A, Nguyen T, Dooley MJ, et al. The prevalence and impact of antimicrobial allergies and adverse drug reactions at an Australian tertiary centre. BMC Infect Dis. 2015;15:572.

6. Park M, Markus P, Matesic D, Li JTC. Safety and effectiveness of a preoperative allergy clinic in decreasing vancomycin use in patients with a history of penicillin allergy. Ann Allergy Asthma Immunol. 2006;97(5):681-7.

7. Barlam TF, Cosgrove SE, Abbo LM, MacDougall C, Schuetz AN, Septimus EJ, et al. Implementing an antibiotic stewardship program: guidelines by the Infectious Diseases Society of America and the Society for Healthcare Epidemiology of America. Clin Infect Dis. 2016;62(10):e51-77.

8. Charneski L, Deshpande G, Smith SW. Impact of an antimicrobial allergy label in the medical record on clinical outcomes in hospitalized patients. Pharmacotherapy. 2011:31(8):742-7.

9. MacLaughlin EJ, Saseen JJ, Malone DC. Costs of ß-lactam allergies: selection and costs of antibiotics for patients with a reported B-lactam allergy. Arch Fam Med. 2000;9(8):722-6.

10. Macy E, Contreras R. Health care use and serious infection prevalence associated with penicillin "allergy" in hospitalized patients: a cohort study. J Allergy Clin Immunol. 2014;133(3):790-6.

11. Sade K, Holtzer I, Levo Y, Kivity S. The economic burden of antibiotic treatment of penicillin-allergic patients in internal medicine wards of a general tertiary care hospital. Clin Exp Allergy. 2003;33:501-6.

12. Trubiano JA, Leung VK, Chu MY, Worth LJ, Slavin MA, Thursky KA. The impact of antimicrobial allergy labels on antimicrobial usage in cancer patients. Antimicrob Resist Infect Control. 2015;4:23.

13. Picard M, Bégin P, Bouchard H, Cloutier J, Lacombe-Barrios J, Paradis J, et al. Treatment of patients with a history of penicillin allergy in a large tertiary-care academic hospital. J Allergy Clin Immunol Pract. 2013;1(3):252-7.

14. Lutomski DM, LaFollette JA, Biaglow MA, Haglund LA. Antibiotic allergies in the medical record: effect on drug selection and assessment of validity. Pharmacotherapy. 2008;28(11):1348-53.

15. Stevens DL, Bisno AL, Chambers HF, Dellinger EP, Goldstein EJC, Gorbach SL, et al. Practice guidelines for the diagnosis and management of skin and soft tissue infections: 2014 update by the Infectious Diseases Society of America. Clin Infect Dis. 2014;59(2):e10-52.

16. Solomkin JS, Mazuski JE, Bradley JS, Rodvold KA, Goldstein EJC, Baron EJ, et al. Diagnosis and management of complicated intra-abdominal infection in adults and children: guidelines by the Surgical Infection Society and the Infectious Diseases Society of America. Clin Infect Dis. 2010;50(2):133-64.

17. Mandell LA, Wunderink RG, Anzueto A, Bartlett JG, Campbell GD, Dean NC, et al. Infectious Diseases Society of America/American Thoracic Society consensus guidelines on the management of community-acquired pneumonia in adults. Clin Infect Dis. 2007;44 Suppl 2:S27-72.

18. Bull AL, Worth LJ, Richards MJ. Impact of vancomycin surgical antibiotic prophylaxis on the development of methicillin-sensitive Staphylococcus aureus surgical site infections: report from Australian Surveillance Data (VICNISS). Ann Surg. 2012;256(6):1089-92.

19. Kim SH, Kim KH, Kim HB, Kim NJ, Kim EC, Oh MD, et al. Outcome of vancomycin treatment in patients with methicillin-susceptible Staphylococcus aureus bacteremia. Antimicrob Agents Chemother. 2008;52(1):192-7.

20. Deshpande A, Pasupuleti V, Thota P, Pant C, Rolston DDK, Sferra TJ, et al. Community-associated Clostridium difficile infection and antibiotics: a meta-analysis. J Antimicrob Chemother. 2013;68(9):1951-61.

21. Wieczorkiewicz JT, Lopansri BK, Cheknis A, Osmolski JR, Hecht DW, Gerding DN, et al. Fluoroquinolone and macrolide exposure predict Clostridium difficile infection with the highly fluoroquinolone- and macrolide-resistant epidemic $C$. difficile strain BI/NAP1/027. Antimicrob Agents Chemother. 2015;60(1):418-23.

22. Arroliga ME, Wagner W, Bobek MB, Hoffman-Hogg L, Gordon SM, Arroliga AC. A pilot study of penicillin skin testing in patients with a history of penicillin allergy admitted to a medical ICU. Chest. 2000;118(4):1106-8.

23. Arroliga ME, Radojicic C, Gordon SM, Popovich MJ, Bashour CA, Melton AL, et al. A prospective observational study of the effect of penicillin skin testing on antibiotic use in the intensive care unit. Infect Control Hosp Epidemiol. 2003;24(5):347-50.

24. Li JTC, Markus PJ, Osmon DR, Estes L, Gosselin VA, Hanssen AD. Reduction of vancomycin use in orthopedic patients with a history of antibiotic allergy. Mayo Clin Proc. 2000;75(9):902-6.

25. Macy E. Elective penicillin skin testing and amoxicillin challenge: effect on outpatient antibiotic use, cost, and clinical outcomes. J Allergy Clin Immunol. $1998 ; 102(2): 281-5$
26. Park MA, McClimon BJ, Ferguson B, Markus PJ, Odell L, Swanson A, et al. Collaboration between allergists and pharmacists increases B-lactam antibiotic prescriptions in patients with a history of penicillin allergy. Int Arch Allergy Immunol. 2011;154(1):57-62.

27. Nadarajah K, Green GR, Naglak M. Clinical outcomes of penicillin skin testing. Ann Allergy Asthma Immunol. 2005;95(6):541-5.

28. Daulat S, Solensky R, Earl HS, Casey W, Gruchalla RS. Safety of cephalosporin administration to patients with histories of penicillin allergy. J Allergy Clin Immunol. 2004;113(6):1220-2.

29. Goodman EJ, Morgan MJ, Johnson PA, Nichols BA, Denk N, Gold BB. Cephalosporins can be given to penicillin-allergic patients who do not exhibit an anaphylactic response. J Clin Anesth. 2001;13(8):561-4.

30. Leis JA, Palmay L, Ho G, Raybardhan S, Gill S, Kan T, et al. Point-of-care ß-lactam allergy skin testing by antimicrobial stewardship programs: a pragmatic multicenter prospective evaluation. Clin Infect Dis. 2017; 65(7): 1059-65.

31. Sacco KA, Bates A, Brigham TJ, Imam JS, Burton MC. Clinical outcomes following inpatient penicillin allergy testing: a systematic review and metaanalysis. Allergy. 2017;72(9):1288-96.

32. Trubiano JA, Beekmann SE, Worth LJ, Polgreen PM, Thursky KA, Slavin $\mathrm{MA}$, et al. Improving antimicrobial stewardship by antibiotic allergy delabeling: evaluation of knowledge, attitude, and practices throughout the emerging infections network. Open Forum Infect Dis. 2016;3(3):ofw153.

33. Trubiano JA, Chen C, Cheng AC, Grayson ML, Slavin MA, Thursky KA; National Antimicrobial Prescribing Survey. Antimicrobial allergy 'labels' drive inappropriate antimicrobial prescribing: lessons for stewardship. J Antimicrob Chemother. 2016;71(6):1715-22.

34. van Dijk SM, Gardarsdottir H, Wassenberg MWM, Oosterheert JJ, de Groot $\mathrm{MCH}$, Rockmann $\mathrm{H}$. The high impact of penicillin allergy registration in hospitalized patients. J Allergy Clin Immunol Pract. 2016;4(5):926-31.

35. Su T, Broekhuizen BDL, Verheij TJM, Rockmann H. The impact of penicillin allergy labels on antibiotic and health care use in primary care: a retrospective cohort study. Clin Transl Allergy. 2017;7:18.

36. MacFadden DR, LaDelfa A, Leen J, Gold WL, Daneman N, Weber E, et al. Impact of reported beta-lactam allergy on inpatient outcomes: a multicenter prospective cohort study. Clin Infect Dis. 2016;63(7):904-10.

37. Vaisman A, McCready J, Hicks S, Powis J. Optimizing preoperative prophylaxis in patients with reported ß-lactam allergy: a novel extension of antimicrobial stewardship. J Antimicrob Chemother. 2017;72(9):2657-60.

Julie Hui-Chih Wu, MSc, is with Public Health Ontario, Toronto, Ontario. Bradley J Langford, BSCPhm, ACPR, PharmD, BCPS, is with Public Health Ontario, Toronto, Ontario.

Kevin L Schwartz, MD, MSC, FRCPC, is with Public Health Ontario and the Dalla Lana School of Public Health, University of Toronto, Toronto, Ontario.

Rosemary Zvonar, BSCPhm, ACPR, FCSHP, is with The Ottawa Hospital, Ottawa, Ontario.

Sumit Raybardhan, BSCPhm, ACPR, MPH, is with North York General Hospital, Toronto, Ontario.

Valerie Leung, BScPhm, ACPR, MBA, is with Public Health Ontario, Toronto, Ontario.

Gary Garber, MD, FRCPC, FACP, FIDSA, CCPE, is with Public Health Ontario and the Department of Medicine, University of Toronto, Toronto, Ontario.

Competing interests: None declared.

\section{Address correspondence to:}

Julie Hui-Chih Wu

Public Health Ontario

480 University Avenue, Suite 300

Toronto ON M5G 1V2

e-mail: juliehc.wu@oahpp.ca

Funding: None received. 